\title{
Characterization of murine macrophages from bone marrow, spleen and peritoneum
}

\author{
Changqi Wang ${ }^{1 *+}$, Xiao Yu ${ }^{1,2+}{ }^{1}$, Qi Cao ${ }^{1}$, Ya Wang ${ }^{1}$, Guoping Zheng ${ }^{1}$, Thian Kui Tan ${ }^{1}$, Hong Zhao ${ }^{1,3}$, Ye Zhao ${ }^{1}$, \\ Yiping Wang ${ }^{1}$ and David $\mathrm{CH}$ Harris $^{1}$
}

\begin{abstract}
Background: Macrophages have heterogeneous phenotypes and complex functions within both innate and adaptive immune responses. To date, most experimental studies have been performed on macrophages derived from bone marrow, spleen and peritoneum. However, differences among macrophages from these particular sources remain unclear. In this study, the features of murine macrophages from bone marrow, spleen and peritoneum were compared.

Results: We found that peritoneal macrophages (PMs) appear to be more mature than bone marrow derived macrophages (BMs) and splenic macrophages (SPMs) based on their morphology and surface molecular characteristics. BMs showed the strongest capacity for both proliferation and phagocytosis among the three populations of macrophage. Under resting conditions, SPMs maintained high levels of pro-inflammatory cytokines expression (IL-6, IL-12 and TNF-a), whereas BMs produced high levels of suppressive cytokines (IL-10 and TGF- $\beta$ ). However, SPMs activated with LPS not only maintained higher levels of (IL-6, IL-12 and TNF-a) than BMs or PMs, but also maintained higher levels of IL-10 and TGF- $\beta$.
\end{abstract}

Conclusions: Our results show that BMs, SPMs and PMs are distinct populations with different biological functions, providing clues to guide their further experimental or therapeutic use.

Keywords: Macrophage, Bone marrow, Spleen, Peritoneum

\section{Background}

Macrophages play an essential role in both innate and adaptive immunity [1]. Macrophages are the indispensable part of the host defense system because of their presence in virtually every type of tissue, their capacity to contain the majority of infections in the early phase of their development, and their ability to mount specific immunological responses.

Macrophages are distributed in all tissues and organs after birth. The distribution patterns of macrophages have been shown by labeling the colony-stimulated factor 1 receptor (Csf1r) promoter with green fluorescent protein (GFP) [2] or by specific F4/80 antibody (Ab) staining of macrophages [3]. It has been found that distinctive morphological differences within and among

\footnotetext{
*Correspondence: cwan5402@uni.sydney.edu.au

'Equal contributors

'Centre for Transplant and Renal Research at Westmead, Sydney, NSW, Australia

Full list of author information is available at the end of the article
}

macrophage populations could be attributed to their heterogeneity [4]. The heterogeneity of macrophages may be important for their diverse and flexible participation in immune responses. Therefore, it is important to examine the phenotypic and functional differences amongst macrophages from different origins, such as spleen, bone marrow and peritoneum.

Peritoneal macrophages (PMs) have been widely used as a macrophage source in mice since the 1960s [5,6]. Possibly due to the low organ tension within the peritoneal cavity, PMs are remarkably distinct from macrophages of other tissues [7]. For example, PMs have higher expression of inducible nitric oxide synthase and IL-12 than do splenic macrophages (SPMs) [8].

SPMs were originally located in the cords of Billroth in splenic red pulp and termed red pulp macrophages, which show a high acid phosphatase activity and several detectable macrophage markers, such as F4/80, Mac-1 and MOMA-2 [9-12]. Previous studies have found that SPMs differ significantly from PMs in their requirements

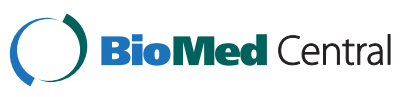


for activation [13], and exhibit different levels of CD40L, IL-1 and scavenger receptors [14,15]. It has been reported in a tumor-bearing mouse study, that cytotoxicity was significantly decreased in PMs, while markedly increased in SPMs [16]. However, the differences of SPMs with other resident macrophages have not been fully addressed.

Another source for commonly used macrophages is the bone marrow. The growth of bone marrow macrophages (BM) requires macrophage colony-stimulating factor (M-CSF). In the past, studies of macrophages have had a bias towards macrophages derived from one specific organ. For instance, BMs have been commonly used due to their homogeneity, ability to be transfected, proliferation capacity and longer lifespan. However, the application of BMs in experimental studies also has difficulty due to the instability of their phenotype and functions in vivo [17]. BMs are relatively flexible in their response to modification; for example, their proliferation can be regulated by changing the concentration of growth factor M-CSF [18].

For those reasons, it is important to define differences among macrophages derived from spleen, bone marrow and peritoneal cavity. The aim of this study was to explore differences in morphology, phenotype, proliferation, phagocytosis, antigen presentation and cytokine expression of murine SPMs, BMs and PMs.

\section{Results}

Morphological difference of SPMs, BMs and PMs

PMs displayed a larger cell size (Figure 1G) and higher lysosomal content than both SPMs and BMs (Figure 1D, $\mathrm{E}$ and F). SPMs had a more elongated spindle shape than PMs and BMs (Figure 1A, B and C), and lower lysosomal content. BMs contained less cytoplasm than PMs or SPMs.

\section{Phenotype differences of SPMs, PMs and BMs}

The expression of CD115, CD206, GR-1, CD80, CD86, MHCII, B7-H1, B7-H2, B7-H3 and B7-H4 was examined by flow cytometry analysis. CD115 was expressed frequently on BMs $(65.4 \pm 3.0 \%)$, and significantly less on SPMs $(2.4 \pm 0.4 \%)$ and PMs $(3.6 \pm 0.2 \%)$. Similarly, Gr-1 exhibited a much more frequent expression on BMs $(56.2 \pm 2.3 \%)$ than on SPMs $(6.6 \pm 0.7 \%)$ or PMs $(8.3 \pm$ $1.1 \%$ ) (Figure 2A, D).

CD80, CD86 and MHC II are important costimulatory molecules for T cell stimulation. PMs demonstrated high frequent expression of MHC II $(25.5 \pm 3.2 \%)$ and CD86 $(45.3 \pm 2.7 \%)$, whereas, BMs had high expression of CD80 (34.6 $\pm 2.6 \%)$. SPMs showed relatively low expression of CD80 (5.5 $\pm 0.8 \%)$ and CD86 (36.1 $\pm 1.9 \%)$ (Figure 2B, D).

Expression of other costimulatory ligands including B7-H1, B7-H2, B7-H3 and B7-H4 was examined by flow
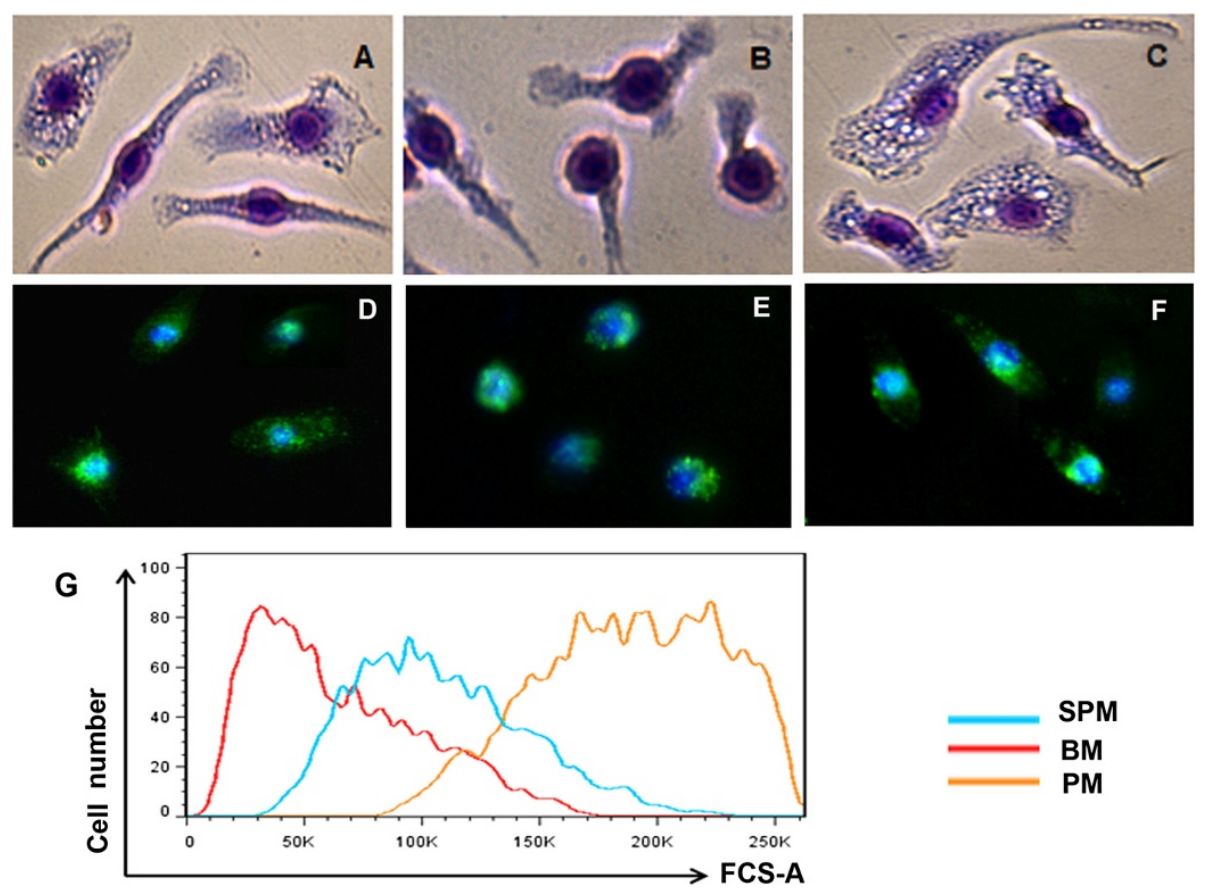

Figure 1 Morphological characteristics of cultured macrophages derived from spleen (A, D), bone marrow (B, E) and peritoneal cavity (C, F), and their cell size assessment (G). All cells were cultured in complete RPMI1640 on 6-well plates, and after removal of supernatant, cells were then stained with Giemsa-wright dye (A, B, C) and to demonstrate lysosome, anti-LAMP1 (D, E, F) (original magnification x400). Cell size was assessed by flow cytometry analysis (G). 


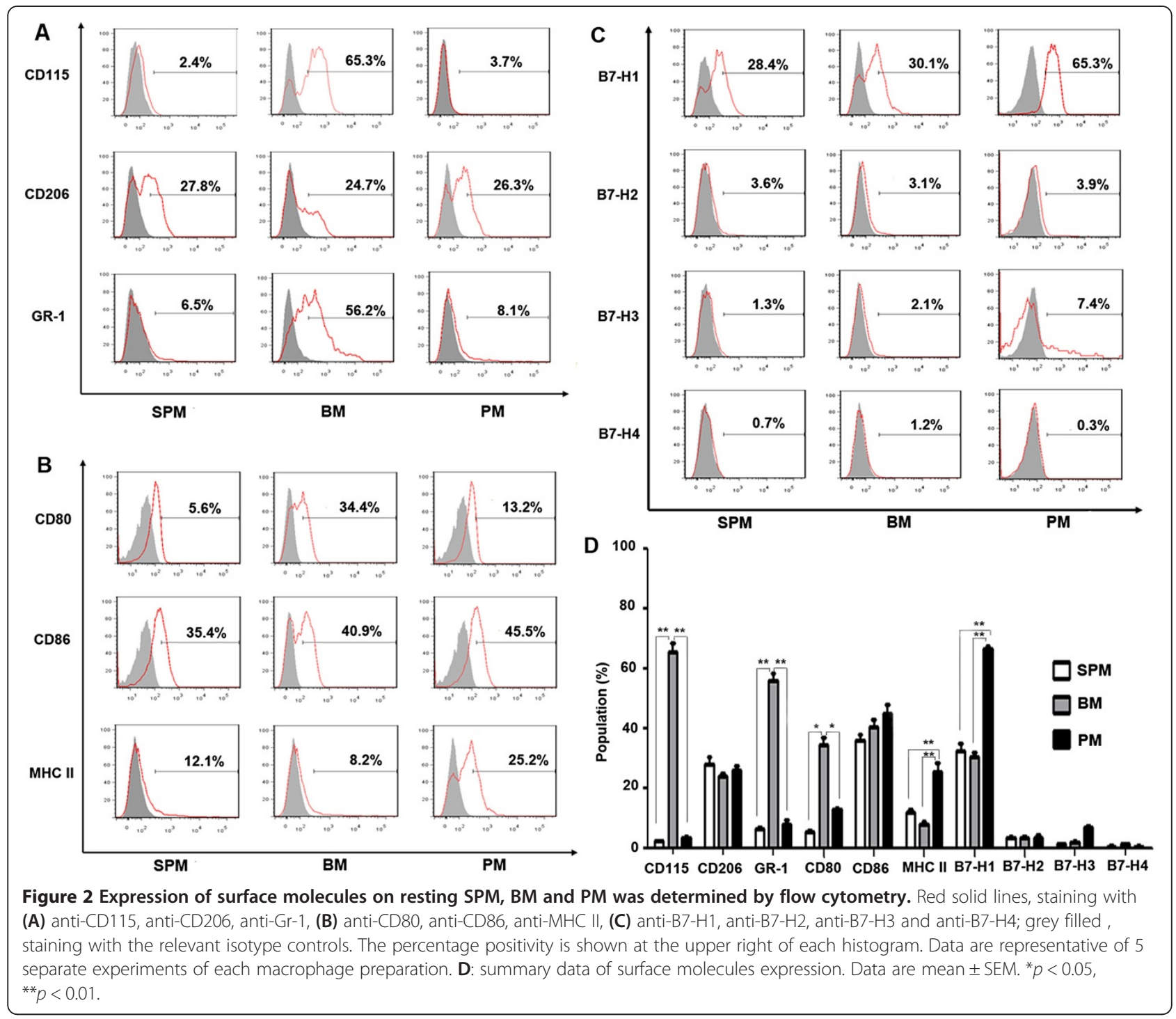

cytometry. The expression of B7-H1 was much more frequent on PMs $(66.7 \pm 0.8 \%)$ than SPMs $(32.5 \pm 2.5 \%)$ or BMs $(30.7 \pm 1.3 \%)$. Low expression level of $\mathrm{B} 7-\mathrm{H} 2$, B7-H3 and B7-H4 was shown for all three macrophage types (Figure 2C, D).

\section{Proliferative capability of SPMs, BMs and PMs}

The proliferative capability of SPMs, BMs and PMs was assessed. Under culture with $2 \mathrm{ng} / \mathrm{ml}$ M-CSF (Figure 3A), BMs showed a much stronger proliferative capability than SPMs and PMs. BM numbers increased from day 4, and continued until to day14 when there was a 60 fold increase over baseline. However, SPMs showed less proliferation with only a 7 fold increase. In contrast, there was no proliferation in PMs during the 14 day culture (Figure 3B).

In response to $10 \mathrm{ng} / \mathrm{ml}$ of $\mathrm{M}$-CSF (Figure 3B), the proliferation of the three macrophage populations showed similar patterns to those with $2 \mathrm{ng} / \mathrm{ml}$ M-CSF. The proliferation of BMs and SPMs was much greater than that in low concentration M-CSF (Figure 3B). However, an increase of M-CSF concentration up to 10 $\mathrm{ng} / \mathrm{ml}$ did not enhance proliferation capability of PMs.

\section{Capacity of phagocytosis}

Phagocytic capacity of these three populations of macrophages was examined. A substantial amount of FITCdextran was taken up by the macrophages derived from the three different sources. BMs $(97.9 \pm 1.2 \%$ of cells) exhibited the highest phagocytotic ability compared to SPMs $(64.7 \pm 3.1 \%)$ and PMs $(78.9 \pm 2.6 \%)$ (Figure $4 \mathrm{~A})$. The mean fluorescence intensity (MFI) of BMs, SPMs and PMs was $1980 \pm 145,645 \pm 29$ and $1232 \pm 77$ respectively (Figure 4B), indicating the higher phagocytotic ability of individual BMs. The MFI value of PMs was 


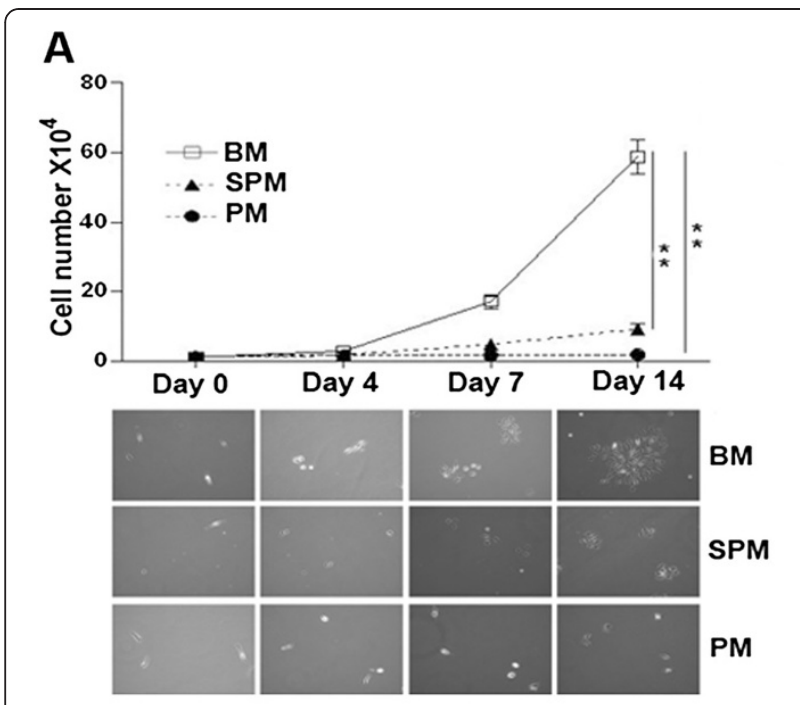

B

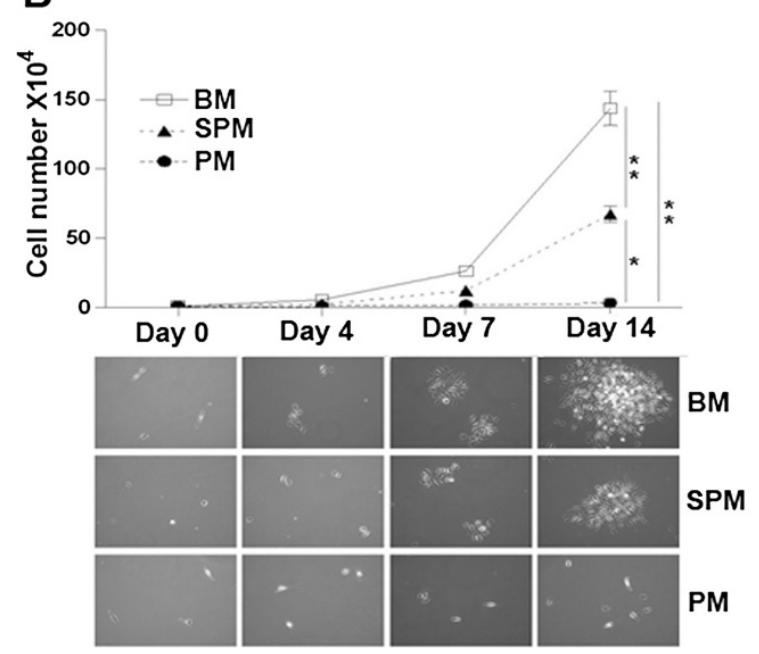

Figure 3 Macrophage growth rate treated with different M-CSF concentrations. BM, SPM and PM were cultured with M-CSF in concentrations of $2 \mathrm{ng} / \mathrm{ml}$ (A) or $10 \mathrm{ng} / \mathrm{ml}$ (B) for 0, 4, 7 and 14 days. The numbers of macrophages were quantified. Images are representative of 3 separate experiments. Data are mean \pm SEM. ${ }^{*} p<0.05,{ }^{* *} p<0.01$.

higher than SPMs indicating the higher phagocytotic capability of PMs.

\section{Antigen presenting capacity}

SPMs, BMs and PMs were analyzed for their ability to present OVA antigen to OVA-specific DO11.10 CD4+ T cells by $[3 \mathrm{H}]$-thymidine incorporation assay. DCs generated from bone marrow were used as positive control. Each of these types of macrophage exhibited a much lower OVA-specific antigen presenting ability than DCs, and there was no significant difference in the ability of presenting OVA-specific antigen among the three types of macrophage (Figure 5).

\section{Cytokine expression profile of SPMs, BMs and PMs}

Cytokine mRNA expression profiles were examined. Under resting conditions, BMs produced significantly higher levels of IL-10 and TGF- $\beta$ than SPMs and PMs. SPMs produced significantly higher levels of IL-6, IL-12 and TNF- $\alpha$ than BMs and PMs. However, following LPS activation, SPMs still expressed high levels of proinflammatory cytokines (IL-6, IL-12 and TNF- $\alpha$ ) in comparison to BMs or PMs. SPMs expressed significantly higher level of suppressive cytokine IL-10 and TGF- $\beta$ than PMs. SPMs also expressed significantly higher level of TGF- $\beta$ than BMs (Figure 6).

\section{Discussion}

Macrophages have heterogeneous phenotypes and complex functions within both innate and adaptive immune responses [19]. To date, most experimental studies have been performed on BMs, isolated SPMs and PMs [1]. However, differences among macrophages from these particular sources remain unclear. In this study, the features of macrophages from spleen, bone marrow and peritoneal cavity were compared. We found that PMs appear to be more mature than SPMs and BMs, based on their morphology and surface molecular characterizatics. BMs showed the strongest capacity in both proliferation and phagocytosis among the three populations of macrophage; under resting conditions, SPMs maintained high level pro-inflammatory cytokine expression (IL-6, IL-12 and TNF- $\alpha$ ), whereas, BMs had high level expression of suppressive cytokines (IL-10 and TGF- $\beta$ ); after LPS activation, SPMs expressed relatively high levels of all those cytokines.

In macrophage studies, macrophage cell lines including J774A.1, RAW264.7, P388D1 and U937 [20,21] can be used, however, continuous subculture of these cell lines may cause gene loss and impair macrophage immune functions. Therefore, macrophages from bone marrow, spleen and peritoneum in primary culture are more commonly used. To date, macrophage studies have been performed and validated extensively using BMs [22-24], but less so with SPMs and PMs. Unlike macrophages obtained directly from spleen and peritoneum, BMs can be fully differentiated in vitro from macrophage dendritic cell precursors [25]. Although there are many advantages in using BMs in immunological studies, such as their high yield, homogeneity and long lifespan [23], the features of BM macrophages are not fully characterized. Morphological changes of macrophages from three sources were examined to compare their maturation. Consistent with the previous studies [26], there are some similarities among SPMs, BMs and PMs with regard to their sphere and deeply stained nuclei, but SPMs and PMs contained much more cytoplasm than BMs, suggesting that BMs may be less mature then SPMs and 


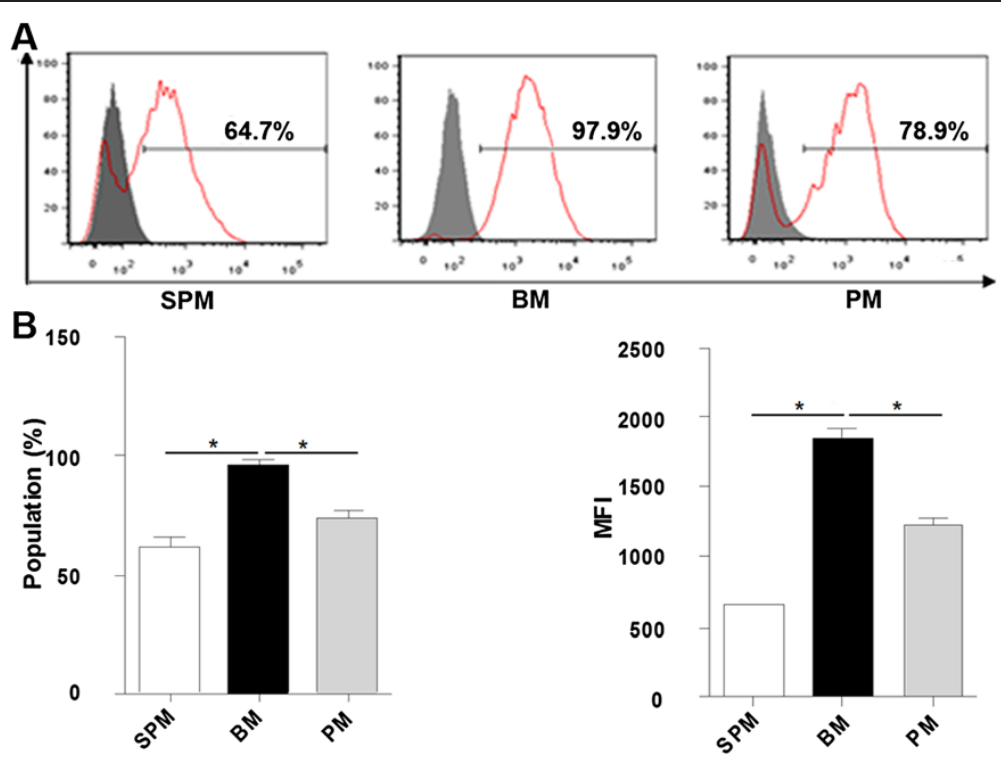

Figure 4 FITC-dextran uptake assay of macrophages from the three different sources. (A) Purified macrophages were incubated with FITCdextran at $37^{\circ} \mathrm{C}$ for $45 \mathrm{~min}$, and then washed extensively to remove excess FITC-dextran, followed by FACS analysis. Representative histograms are shown. Solid grey histograms represent control groups; solid red lines represent the percentage of phagocytic macrophages. (B) Group histograms showing both population and median fluorescence intensity (MFI) values. Data are the mean \pm SEM from five separate experiments. ${ }^{*} p<0.05$.

PMs. When comparing cytoplasm of SPMs with PMs, PMs exhibited a larger size and lysosomal content than SPMs, suggesting that PMs may be more mature than SPMs. In addition to morphological analysis, surface molecular expression could also be used, at least in part, to indicate the maturity of the three populations. A study from Alatery showed that both SPMs and BMs were not fully mature and needed to undergo a further maturation in vitro in culture [26]. Our study detected

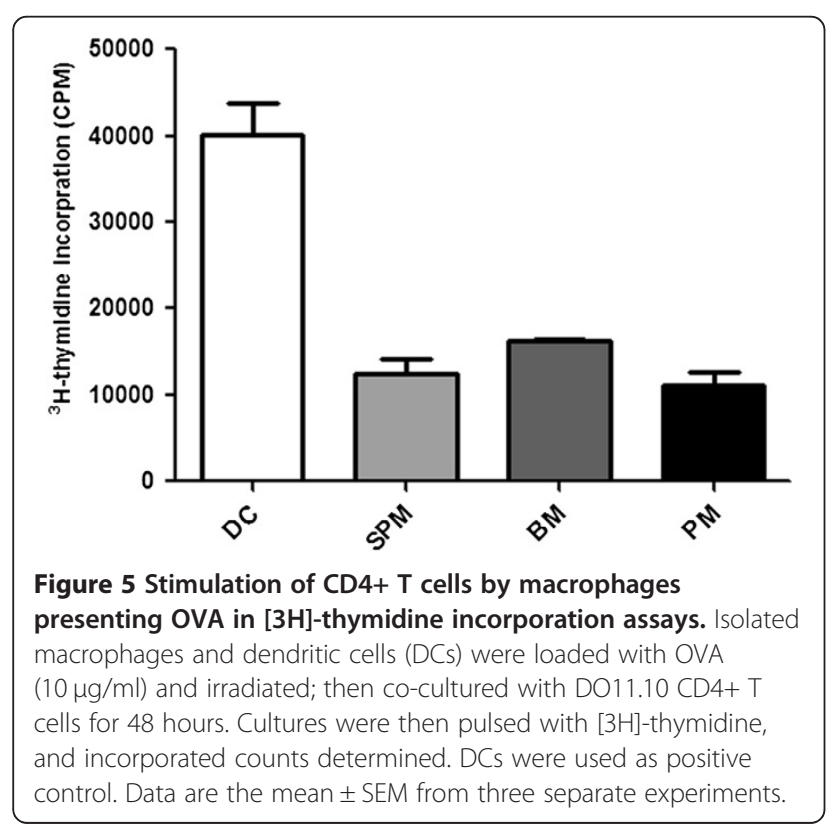

surface molecular expression that related to macrophage maturation and function. PMs had high level MHC II and CD86 expression, whereas BMs had high level CD115 and GR-1 expression. MHC II and CD86 are expressed highly on fully functional macrophages, which also indicates their maturity $[27,28]$. CD115 and Gr1 are usually expressed on precursors of monocytes and macrophages, indicating that the cells are less differentiated and more immature [29]. Therefore, our study showed that PMs appear to be the most mature macrophage, followed by SPMs, then BMs. These differences are likely important considerations in the experimental use of macrophages from different sources.

Following great technical improvements in the in vitro generation of macrophages, they are now considered as candidates for cell therapy [17,30-32]. Currently, there is a much variation in the preparation of macrophages from different sources for therapeutic use. A recent study of muscle regeneration demonstrated the therapeutic potential of macrophages derived from bone marrow [33]. However, both the experimental and clinical use of regulatory macrophages (M2) for treating central nervous system injury relied on generation of macrophages from peripheral blood. Previously we have demonstrated the therapeutic efficacy of M2 macrophages derived from spleen, but not bone marrow, to resolve inflammation and repair the kidney injury [34-37]. We have shown a similar efficacy of M2 macrophages derived from peritoneum as from spleen (unpublished data). This demonstrates the importance of the origin of 


\section{IL-10}

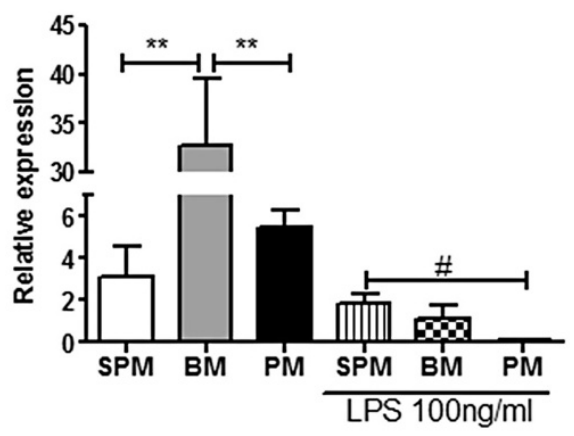

IL-6

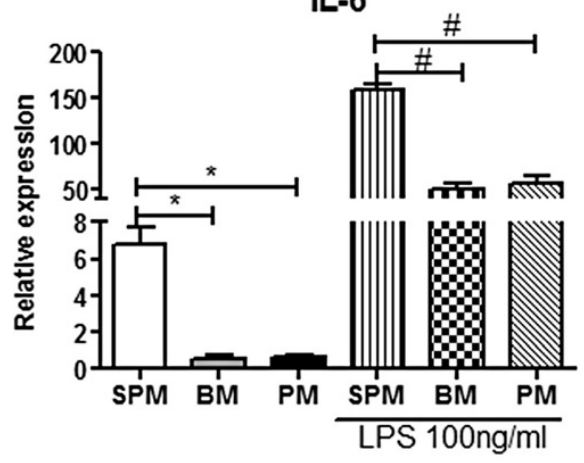

$\mathrm{TNF}-\alpha$

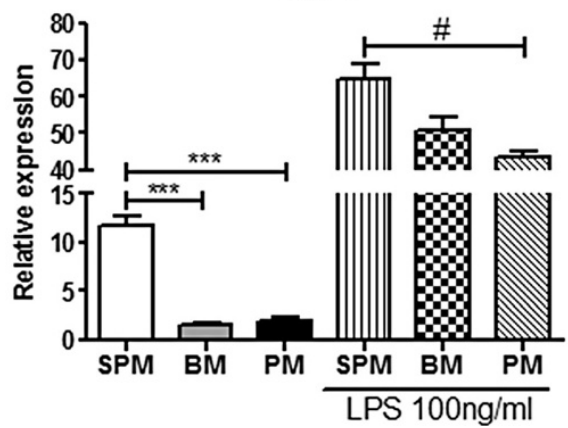

TGF- $\beta$

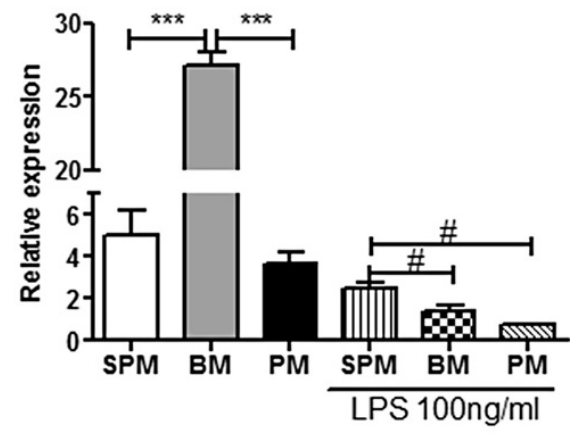

IL-12

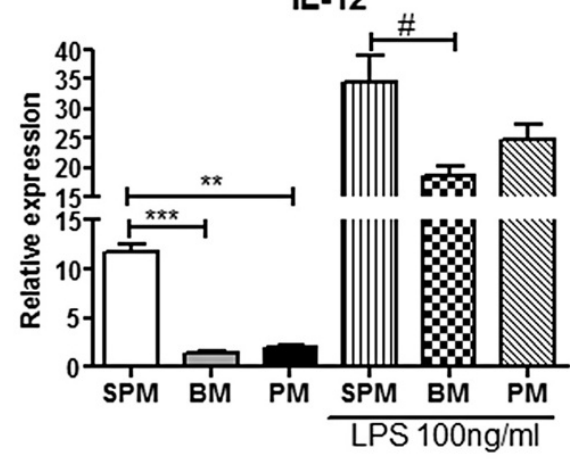

Figure 6 Cytokine mRNA expression profiles of the three populations (SPMs, BMs and PMs) with and without activation with LPS. mRNA levels of IL-10, TGF- $\beta$, IL-6, IL-12 and TNF- $\alpha$ in SPMs, BMs and PMs were measured by real time PCR with $\beta$-actin as the housekeeping gene; $(n=5)$. Values are expressed as 10x (gene of interest vs $\beta$-actin). ${ }^{*} p<0.05,{ }^{* *} p<0.01,{ }^{* * *} p<0.001$.

macrophages used for treating disease. In this present study, the proliferative, phagocytotic and antigen presenting ability of BMs, SPMs, and PMs were assessed. It was found that BMs exhibited the strongest proliferative capability among the three populations, with SPMs demonstrating slight and PMs no proliferative capability, suggesting that macrophages derived from spleen and peritoneum might be more functionally and phenotypically stable. This observation is consistent with our previous report that M2 macrophage generated from bone marrow rather than spleen showed strong proliferation in vivo and failed to protect against renal disease, apparently due to the loss of function and phenotype of macrophages linked to their proliferation ability [35]. In addition to proliferative ability, phagocytotic capacity of macrophages was assessed. BMs have been shown to maintain the highest capability of phagocytosis $[38,39]$, which was confirmed in our study and may be an important consideration in regards to their therapeutic efficacy.

T-cell activation and proliferation is associated with many chronic inflammatory diseases, including chronic kidney disease, rheumatoid arthritis and atherosclerosis $[17,40,41]$. Inhibition of T-cell activation is important in effectively suppressing inflammatory responses. A previous study showed that $\mathrm{B} 7-\mathrm{H} 1$ binding to its receptor, $\mathrm{PD}-$ 1 , results in inhibition of antigen-induced T-cell activation 
[42]. High expression of B7-H1 on PMs suggests PMs might inhibit T cell activation more effectively than SPMs or BMs. Such a property of PMs indicates a greater potential for treating chronic inflammatory diseases.

Although SPMs, BMs and PMs exhibited different levels of expression of molecules involved in antigen presentation, such as MHCII, CD80 and CD86, they showed similar antigen presenting ability. Many PMs are recruited into peritoneal cavity in response to bacterial infection, in greater amount than other cell types $[43,44]$. In spleen, several subpopulations of macrophage have been characterized in vivo, including $\mathrm{F} 4 / 80+$ red pulp macrophages, MOMA-1+ marginal metallophilic macrophages, ER-TR9+ marginal zone macrophages and MOMA-2+ white pulp macrophages in mice [7]. F4/80 is prodominantly expressed on red pulp macrophages, but not on others such as marginal metallophilic macrophages, marginal zone macrophages and white pulp macrophages. Therefore, F4/80 stained cells might be less diverse and could be considered as a relative uniform population. However, other subpopulations of splenic macrophages require further study.

Comparison of cytokine expression profile of SPMs, BMs and PMs might contribute to the understanding of their distinct properties and provide a valuable reference for further macrophage related studies. The significantly higher expression of TGF- $\beta$ and IL-10 by resting BMs in comparison to SPMs and PMs suggests that in vitro generated BMs might be potentially more likely to have a M2 phenotype. M-CSF has been shown to induce differentiation of BMs from bone marrow progenitors [45] and also to induce human macrophages into a M2 phenotype [46]. Compared to an only 1 day in vitro incubation time of SPMs and PMs, the requirement of 7 days stimulation of bone marrow cells with M-CSF may push them towards M2 differentiation. Combined with high proliferation and phagocytosis ability of BM, thus suggests that BMs might be less mature and phenotypically stable than SPMs and PMs, giving caution to the use of BMs in cell therapy. Alternatively, pro-inflammatory cytokines including IL-6, IL-12 and TNF- $\alpha$ were significantly more highly expressed on SPMs with and without activation than BMs or PMs, which may be relevant to the specific microenvironment of spleen. In spleen, SPMs play an important role in removal of red cells, which may require SPMs to produce abundant cytotoxicity-associated cytokines such as IL-12, TNF- $\alpha$ and IL-6 [47,48]. Therefore, cytokine expression of BMs, SPMs and PMs reflect their biological function.

\section{Conclusions}

In summary, we report a side-by-side comparison study of macrophages derived from spleen, bone marrow and peritoneum. This study demonstrates their distinct characteristics which are likely relevant to their respective roles in immune response. It also provides a powerful reference for choosing macrophages of specific origins not only for experimental study but also for therapeutic use.

\section{Methods}

\section{Animals}

Six- to eight-week-old male BALB/c mice purchased from the Animal Resources Centre (Perth, Australia) were used in this study. DO11.10 mice were obtained from Animal House of Westmead Hospital (Animal Care Facility, Westmead Hospital, NSW, Australia). All animal experiments were approved by the Animal Ethics Committee of the Sydney West Area Health Service. All mice were housed in a specific pathogen-free environment and were maintained under constant temperature $\left(22^{\circ} \mathrm{C}\right)$ and humidity, on a 12-hour light/dark cycle in the Animal House of Westmead Hospital. Then, mice were fed with acidified water and commercial mouse chow (protein 18.9\%; Glen Forrest Stockfeeders, Glen Forrest, WA, Australia) ad libitum. Mice were sacrificed by $\mathrm{CO}_{2}$ inhalation.

\section{Preparation of SPMs, BMs, PMs, DCs and CD4+ T cells}

Mice were sacrificed by $\mathrm{CO}_{2}$ inhalation. Spleens were dissected from abdominal cavity and filtered through a $40-\mu \mathrm{m}$ nylon strainer. Red cell lysis buffer was used to remove red cells. A single splenic cell suspension then was obtained. FACS sorting was performed to obtain F4/ 80 positive and CD11c negative cells; then the harvested cells $\left(0.5-1 \times 10^{6}\right)$ were cultured for 24 hours with complete RPMI1640 supplemented with 10\% FBS, 2 mM L-glutamine, $50 \mathrm{U} / \mathrm{ml}$ penicillin, $50 \mu \mathrm{g} / \mathrm{ml}$ streptomycin, 10 mM HEPES (N-2-hydroxyethylpiperazine-N'-2ethanesulfoinc acid) and $0.1 \mathrm{mM}$ nonessential amino acids (all from Life Technologies) and $10 \mathrm{ng} / \mathrm{ml} \mathrm{M-CSF}$ (R\&D Systems) in 6-well plates (BD Bioscience), at $37^{\circ} \mathrm{C}$. For macrophage activation, cells were stimulated with $100 \mathrm{ng} / \mathrm{ml}$ LPS (Sigma) for 24 hours. The cells were harvested by trypsin (0.5\%) (Invitrogen).

Pelvic and femoral bones were dissected; and all the remaining tissue on the bones was removed. Each bone end was cut off, and bone marrow was expelled. Cells from bone marrow were cultured for 7 days with $10 \mathrm{ng} / \mathrm{ml} \mathrm{M-CSF}$; medium was changed every two days. Adherent cells were detached by trypsin (0.5\%) digestion. FACS sorting (BD Bioscience) was performed to obtain F4/80 positive and CD11c negative cells; then the harvested cells $\left(0.5-1 \times 10^{6}\right)$ were cultured for 24 hours in complete RPMI1640 with 10\% FBS in 6-well plates, at $37^{\circ} \mathrm{C}$. For macrophage activation, cells were stimulated with 100ng/ml LPS (Sigma) for 24 hours. The cells were harvested by trypsin $(0.5 \%)$. 
Table 1 Antibodies for flow cytometry analysis

\begin{tabular}{ll}
\hline Antibody & Flurochrome \\
\hline anti-mouse F4/80 & PE-conjugated \\
anti-mouse CD11C & APC-conjugated \\
anti-mouse CD80 & PE-conjugated \\
anti-mouse CD86 & PE-conjugated \\
anti-mouse CD115 & PE-conjugated \\
anti-mouse CD206 & APC-conjugated \\
anti-mouse Gr-1 & PECy7-conjugated \\
anti-mouse MHC II & PE-conjugated \\
anti-mouse B7-H1 & PE-conjugated \\
anti-mouse B7-H2 & PE-conjugated \\
anti-mouse B7-H3 & PE-conjugated \\
anti-mouse B7-H4 & PE-conjugated \\
\hline
\end{tabular}

All antibodies were from eBioscience.

Peritoneal membrane was separated from under the abdominal musculature. 5-7 $\mathrm{ml}$ ice cold PBS was injected into peritoneal cavity; peritoneum was gently and completely massaged; PBS was then aspirated from peritoneal cavity. Peritoneal cells were enriched by centrifugation, then purified by FACS sorting by selecting F4/80 positive and CD11c negative population, then the harvested cells $\left(0.5-1 \times 10^{6}\right)$ were cultured for 24 hours in complete RPMI1640 with 10\% FBS in 6-well plates, at $37^{\circ} \mathrm{C}$. For macrophage activation, cells were stimulated with $100 \mathrm{ng} / \mathrm{ml}$ LPS (Sigma) for 24 hours. The cells were harvested by trypsin $(0.5 \%)$. The purity of detached cells was assessed by Flow analysis (Additional file 1).

To obtain dendritic cells, cells from bone marrow were cultured for 7 days with $10 \mathrm{ng} / \mathrm{ml} \mathrm{GM-CSF}$ and $10 \mathrm{ng} / \mathrm{ml}$ IL-4; medium was changed every two days. Floating cells were removed by PBS washing, adherent cells were considered as DCs.

OVA-specific CD4+ T cells were isolated from DO11.10 mice. DO11.10 mice were sacrificed by $\mathrm{CO}_{2}$ inhalation. Spleen were dissected from abdominal cavity and filtered through a $40-\mu \mathrm{m}$ nylon strainer. Red cell lysis buffer was used to remove red cells. A single splenic cell suspension then was obtained and incubated with mouse CD4 MicroBeads (Miltenyi Biotec) for $15 \mathrm{~min}$ on ice. MACSbead separation was performed to obtain CD4+ T cells.

\section{Gimesa-Wright staining and lysosome staining}

Cells were cultured in 6-well plates and fixed by $100 \%$ methanol for $10 \mathrm{~min}$ at $-20^{\circ} \mathrm{C}$; and after air-drying, $1 \mathrm{ml}$ of Gimesa-Wright dye (Sigma) was added into each well for $3 \mathrm{~min}$ at room temperature and then washed with PBS completely. Stained cells were examined under microscopy (Nikon) with magnification $\mathrm{x} 400$. For lysosome staining, cells were fixed by $100 \%$ methanol for $10 \mathrm{~min}$ at $-20^{\circ} \mathrm{C}$. Anti-mouse lysosome associated membrane protein 1 (LAMP1) (1/400; Abcam) was used as primary antibody and Alexa Fluor ${ }^{\circledR} 488$ (green) goat anti-rabbit IgG (1/1000; eBioscience) was used as second antibody. DAPI was used to stain the cell nuclei (blue). Images were captured by fluorescent microscope (Olympus) with magnification $\mathrm{x} 400$.

\section{Flow cytometry analysis}

The macrophages were resuspended in PBS containing $2 \%$ fetal bovine serum (FBS). Non-specific Ab binding was blocked with addition of Fc block $A b$, then fluorochrome-labelled Abs against macrophage surface markers were added in a concentration of 1:200; cells were stained for $20 \mathrm{~min}$ on ice and washed 3 times with cold PBS. Unstained samples were prepared for cell size assessment. Data were collected with Flow Cytometer LSRII and analyzed with Flow Jo software. Abs used in this study are listed in Table 1.

\section{Proliferation assay}

Macrophages derived from spleen, bone marrow and peritoneal cavity were purified. Then, purified macrophages were cultured in separate 6-well plates at the concentration of $1 \times 10^{4}$ cells per well. Medium used was complete RPMI 1640 with M-CSF in two concentrations $(10 \mathrm{ng} / \mathrm{ml}$ and $2 \mathrm{ng} / \mathrm{ml}$ ). Medium was changed every two days. The cell number was measured by counting under microscope, on days 4, 7 and 14 .

\section{FITC-dextran uptake assay}

In order to measure macrophage phagocytic ability, the FITC-dextran uptake assay was set up by incubating cells with FITC-dextran in triplicate plates. Briefly, purified macrophages were cultured on 12-well plates at a concentration of $0.5 \times 10^{5}$ cells/well. FITC-dextran was added into

Table 2 Primers for real time PCR

\begin{tabular}{lll}
\hline Gene & Sequences of primers & \\
\hline$\beta$-actin & Left:5'-GATTACTGCTCTGGCTCCTAG-3' & Right:5'-GCCACCGATCCACACAGAGT-3' \\
IL-10 & Left:5'-CCAGTACAGCCGGGAGACA-3' & Right:5'-CAGCTGGTCCTTTGTTTGAAAG-3' \\
TGF- $\beta$ & Left:5'-TTAGGAAGGACCTGGGTTGG-3' & Right:5'-AGGGCAAGGACCTTGCTGTA-3' \\
IL-6 & Left:5'-CACAAGTCCGGAGAGGAGAC-3' & Right:5'-TTGCCATTGCACAACTCTIT-3' \\
IL-12 & Left:5'-GACATCACACGGGACCAAAC-3' & Right:5'-TACCAAGGCACAGGGTCATC-3' \\
TNF-a & Left:5'-TGCCTATGTCTCAGCCTCTTC-3' & Right: 5'-GAGGCCATTTGGGAACTTCT-3' \\
\hline
\end{tabular}


each well at a final concentration of $0.5 \mathrm{mg} / \mathrm{ml}$, and the culture plates was incubated at $4^{\circ} \mathrm{C}$ and $37^{\circ} \mathrm{C}$ for $45 \mathrm{~min}$. After incubation, wells were washed extensively to remove excess FITC-dextran. Macrophages were detached by digestion with $5 \%$ trypsin. FACS analysis was performed; median fluorescence intensity (MFI) was calculated.

\section{[3H] thymidine incorporation assay}

For analysis of in vitro T cell proliferation, isolated macrophages and dendritic cells (DCs) were incubated with 10 $\mu \mathrm{g} / \mathrm{ml}$ ovalbumin (OVA) peptide 323-339 (Genscript, USA) for $60 \mathrm{~min}$ at $37^{\circ} \mathrm{C}$. OVA-loaded cells were washed 3 times with RPMI 1640. A total number of 50,000 naive CD4+ T cells were cultured in 96-well plates with 50,000 OVA-loaded macrophages or DCs for 48 hours; then $3 \mathrm{H}-$ Thymidine $(1 \mu \mathrm{Cr} /$ well $)$ was added and the incubation continued for a further 16 hours. Cells were harvested using a Packard Filtermate Harvester 96 and counted by Microbeta counter (PerkinElmer, Beaconsfield, UK).

\section{Real time PCR analysis}

RNA was extracted using the Qiagen (MD, USA) RNeasy mini kit according to the manufacturer's instructions; For reverse transcription, first strand cDNA was transcribed from total RNA using a First Strand cDNA Synthesis Kit ((Fermantas, Australia) by following the manufacturer's instructions. Then the SBYR Green qPCR Detection System (Invitrogen) was employed for real-time PCR. Real-time PCR amplification was carried out in Corbett Rotorgene 6000 real-time Thermo cycler using a PCR mixture containing primers, cDNA and SYBR green mastermix. Levels of mRNA expression were normalized to housekeeping gene $\beta$-actin mRNA levels. GraphPad Prism 5.0 was used for statistical analysis. The primers used in this study are listed on Table 2.

\section{Statistical methods}

The Student's $T$-test was used for 2-group comparisons, and ANOVA was used for comparisons involving 3 or more groups. A P value of less than 0.05 was considered statistically significant. Values are expressed as means \pm standard error (SEM).

\section{Additional file}

Additional file 1: SPMs, BMs and PMs were generated respectively, and then stained with anti-F4/80 and anti-CD11C, the gating of F4/80+ and CD11c-cells was based their isotype controls. Data are representive of 5 separate experiments.

\section{Authors' contributions}

$\mathrm{CW}$ and $\mathrm{XY}$ performed all the experiments under the supervision of D C.H. H and YW. QC and all other authors contributed to the experimental design. CW wrote the manuscript; D C.H. H and YW revised the manuscript. All authors approved the manuscript.

\section{Acknowledgements}

This study was supported by the National Health \& Medical Research Council of Australia (NHMRC, grant 457345 to Yiping Wang \& David Harris).

\section{Author details}

${ }^{1}$ Centre for Transplant and Renal Research at Westmead, Sydney, NSW, Australia. ${ }^{2}$ Department of Urology, Tongji Hospital, Tongji Medical College, Huazhong University of Science and Technology, Wuhan, PR China. ${ }^{3}$ Department of Biochemistry and Molecular Biology, Shanxi Medical University, Shanxi, PR China.

Received: 4 September 2012 Accepted: 25 January 2013

Published: 5 February 2013

\section{References}

1. Gordon S: The macrophage: past, present and future. Eur J Immunol 2007, 37(Suppl 1):S9-S17.

2. Sasmono RT, Oceandy D, Pollard JW, Tong W, Pavli P, Wainwright BJ, Ostrowski MC, Himes SR, Hume DA: A macrophage colony-stimulating factor receptor-green fluorescent protein transgene is expressed throughout the mononuclear phagocyte system of the mouse. Blood 2003, 101:1155-1163.

3. Hume DA, Ross IL, Himes SR, Sasmono RT, Wells CA, Ravasi T: The mononuclear phagocyte system revisited. I Leukoc Biol 2002, 72:621-627.

4. Shortman K, Wu L: Are dendritic cells end cells? Nat Immunol 2004, 5:1105-1106.

5. Rous P: The Relative Reaction within Living Mammalian-Tissues: li. On the Mobilization of Acid Material within Cells, and the Reaction as Influenced by the Cell State. J Exp Med 1925, 41:399-411.

6. Kaufmann SH, Schaible UE: Antigen presentation and recognition in bacterial infections. Curr Opin Immunol 2005, 17:79-87.

7. Liu G, Xia XP, Gong SL, Zhao Y: The macrophage heterogeneity: difference between mouse peritoneal exudate and splenic F4/80+ macrophages. J Cell Physiol 2006, 209:341-352.

8. Zhu YN, Yang YF, Ono S, Zhong XG, Feng YH, Ren YX, Ni J, Fu YF, Tang W, Zuo JP: Differential expression of inducible nitric oxide synthase and IL12 between peritoneal and splenic macrophages stimulated with LPS plus IFN-gamma is associated with the activation of extracellular signalrelated kinase. Int Immunol 2006, 18:981-990.

9. Springer T, Galfre G, Secher DS, Milstein C: Mac-1: a macrophage differentiation antigen identified by monoclonal antibody. Eur J Immunol 1979, 9:301-306.

10. Austyn JM, Gordon S: F4/80, a monoclonal antibody directed specifically against the mouse macrophage. Eur J Immunol 1981, 11:805-815.

11. Hume DA, Robinson AP, MacPherson GG, Gordon S: The mononuclear phagocyte system of the mouse defined by immunohistochemical localization of antigen F4/80. Relationship between macrophages, Langerhans cells, reticular cells, and dendritic cells in lymphoid and hematopoietic organs. J Exp Med 1983, 158:1522-1536.

12. Kraal G, Rep M, Janse M: Macrophages in T and B cell compartments and other tissue macrophages recognized by monoclonal antibody MOMA-2. An immunohistochemical study. Scand J Immunol 1987, 26:653-661.

13. Lane TE, Wu-Hsieh BA, Howard DH: Gamma interferon cooperates with lipopolysaccharide to activate mouse splenic macrophages to an antihistoplasma state. Infect Immun 1993, 61:1468-1473.

14. Kim JG, Keshava C, Murphy AA, Pitas RE, Parthasarathy S: Fresh mouse peritoneal macrophages have low scavenger receptor activity. $J$ Lipid Res 1997, 38:2207-2215.

15. Yang $X$, Ye RG, Kong $\mathrm{QY}$, Yang $\mathrm{QQ}$, Gao $\mathrm{Y}$, Zhong JH, Wang T: CD40 ligand expression on macrophages during peritonitis in continuous ambulatory peritoneal dialysis patients. Adv Perit Dial 2000, 16:213-215.

16. Gordon S: Pathogen recognition or homeostasis? APC receptor functions in innate immunity. C R Biol 2004, 327:603-607.

17. Wang Y, Harris DC: Macrophages in renal disease. J Am Soc Nephrol 2011 , 22:21-27.

18. Hume DA, Gordon S: Regulation of bone-marrow macrophage proliferation. Adv Exp Med Biol 1982, 155:261-266.

19. Gordon S: The role of the macrophage in immune regulation. Res Immunol 1998, 149:685-688.

20. Goodrum KJ: Complement component $\mathrm{C} 3$ secretion by mouse macrophage-like cell lines. J Leukoc Biol 1987, 41:295-301. 
21. Baek YS, Haas S, Hackstein H, Bein G, Hernandez-Santana M, Lehrach $H$, Sauer S, Seitz H: Identification of novel transcriptional regulators involved in macrophage differentiation and activation in U937 cells. BMC Immunol 2009, 10:18.

22. Wells CA, Ravasi T, Faulkner GJ, Carninci P, Okazaki Y, Hayashizaki Y, Sweet $M$, Wainwright BJ, Hume DA: Genetic control of the innate immune response. BMC Immunol 2003, 4:5.

23. Weischenfeldt J, Porse B: Bone Marrow-Derived Macrophages (BMM): Isolation and Applications. CSH Protoc 2008, 2008:pdb prot5080.

24. Marim FM, Silveira TN, Lima DS Jr, Zamboni DS: A method for generation of bone marrow-derived macrophages from cryopreserved mouse bone marrow cells. PLoS One 2010, 5:e15263.

25. Geissmann F, Manz MG, Jung S, Sieweke MH, Merad M, Ley K: Development of monocytes, macrophages, and dendritic cells. Science 2010, 327:656-661.

26. Alatery A, Basta S: An efficient culture method for generating large quantities of mature mouse splenic macrophages. J Immunol Methods 2008, 338:47-57.

27. Andreesen R, Brugger W, Scheibenbogen C, Kreutz M, Leser HG, Rehm A, Lohr GW: Surface phenotype analysis of human monocyte to macrophage maturation. J Leukoc Biol 1990, 47:490-497.

28. Wang Y, Cui X, Tai G, Ge J, Li N, Chen F, Yu F, Liu Z: A critical role of activin $A$ in maturation of mouse peritoneal macrophages in vitro and in vivo. Cell Mol Immunol 2009, 6:387-392.

29. Huang B, Pan PY, Li Q, Sato Al, Levy DE, Bromberg J, Divino CM, Chen SH: $\mathrm{Gr}-1+\mathrm{CD} 115+$ immature myeloid suppressor cells mediate the development of tumor-induced T regulatory cells and T-cell anergy in tumor-bearing host. Cancer Res 2006, 66:1123-1131.

30. Arnold L, Henry A, Poron F, Baba-Amer Y, van Rooijen N, Plonquet A, Gherardi RK, Chazaud B: Inflammatory monocytes recruited after skeletal muscle injury switch into antiinflammatory macrophages to support myogenesis. J Exp Med 2007, 204:1057-1069.

31. Brown BN, Ratner BD, Goodman SB, Amar S, Badylak SF: Macrophage polarization: an opportunity for improved outcomes in biomaterials and regenerative medicine. Biomaterials 2012, 33:3792-3802.

32. Nelson PJ, Rees AJ, Griffin MD, Hughes J, Kurts C, Duffield J: The renal mononuclear phagocytic system. J Am Soc Nephrol 2012, 23:194-203.

33. Ruffell D, Mourkioti F, Gambardella A, Kirstetter P, Lopez RG, Rosenthal N, Nerlov C: A CREB-C/EBPbeta cascade induces M2 macrophage-specific gene expression and promotes muscle injury repair. Proc Natl Acad Sci U S A 2009, 106:17475-17480.

34. Wang Y, Cao Q, Zheng G, Lee W, Zheng D, Li X, Tan TK, Harris DC: By homing to the kidney, activated macrophages potently exacerbate renal injury. Am J Pathol 2008, 172:1491-1499.

35. Cao Q, Zheng D, Sun Y, Wang Y, Lee WW, Zheng G, Alexander SI, Harris DC Impaired alternative activated macrophages from bone marrow in treatment of CKD: Associations with their proliferation in inflamed kidney. Presented in abstract form at the annual meeting of the American Society of Nephrology; October 27 through November 1, 2009. San Diego, CA.

36. Cao Q, Wang C, Zheng D, Wang Y, Lee WW, Wang YM, Zheng G, Tan TK, Yu D, Alexander SI, Harris DC: IL-25 Induces M2 Macrophages and Reduces Renal Injury in Proteinuric Kidney Disease. J Am Soc Nephrol 2011, 22:1229-1239.

37. Zheng D, Wang Y, Cao Q, Lee WW, Zheng G, Sun Y, Tan TK, Alexander SI, Harris DC: Transfused macrophages ameliorate pancreatic and renal injury in murine diabetes mellitus. Nephron Exp Nephrol 2011, 118:e87-99.

38. Mitchison NA: The immunogenic capacity of antigen taken up by peritoneal exudate cells. Immunology 1969, 16:1-14.

39. Cannon GJ, Swanson JA: The macrophage capacity for phagocytosis. J Cell Sci 1992, 101(Pt 4):907-913.

40. Zhou X, Nicoletti A, Elhage R, Hansson GK: Transfer of CD4(+) T cells aggravates atherosclerosis in immunodeficient apolipoprotein $\mathrm{E}$ knockout mice. Circulation 2000, 102:2919-2922.

41. Isomaki P, Clark JM, Panesar M, Cope AP: Pathways of T cell activation and terminal differentiation in chronic inflammation. Curr Drug Targets Inflamm Allergy 2005, 4:287-293.

42. Petroff MG, Kharatyan E, Torry DS, Holets L: The immunomodulatory proteins $\mathrm{B} 7-\mathrm{DC}, \mathrm{B} 7-\mathrm{H} 2$, and $\mathrm{B} 7-\mathrm{H} 3$ are differentially expressed across gestation in the human placenta. Am J Pathol 2005, 167:465-473.

43. Anderson CF, Mosser DM: A novel phenotype for an activated macrophage: the type 2 activated macrophage. J Leukoc Bio/ 2002, 72:101-106.

44. Millard AL, Mertes PM, Ittelet D, Villard F, Jeannesson P, Bernard J: Butyrate affects differentiation, maturation and function of human monocyte-derived dendritic cells and macrophages. Clin Exp Immunol 2002, 130:245-255.
45. Warren MK, Vogel SN: Bone marrow-derived macrophages: development and regulation of differentiation markers by colony-stimulating factor and interferons. J Immunol 1985, 134:982-989.

46. Xu W, Schlagwein N, Roos A, van den Berg TK, Daha MR, van Kooten C: Human peritoneal macrophages show functional characteristics of $M$ CSF-driven anti-inflammatory type 2 macrophages. Eur J Immunol 2007. 37:1594-1599.

47. Gately MK, Wolitzky AG, Quinn PM, Chizzonite R: Regulation of human cytolytic lymphocyte responses by interleukin-12. Cell Immunol 1992, 143:127-142.

48. Galligioni E, Favaro D, Santarosa M, Quaia M, Spada A, Freschi A, Alberti D: Induction and maintenance of monocyte cytotoxicity during treatment with liposomes containing muramyl tripeptide despite tachyphylaxis to the cytokine response. Clin Cancer Res 1995, 1:493-499.

doi:10.1186/1471-2172-14-6

Cite this article as: Wang et al:: Characterization of murine macrophages from bone marrow, spleen and peritoneum. BMC Immunology 2013 14:6.

\section{Submit your next manuscript to BioMed Central and take full advantage of:}

- Convenient online submission

- Thorough peer review

- No space constraints or color figure charges

- Immediate publication on acceptance

- Inclusion in PubMed, CAS, Scopus and Google Scholar

- Research which is freely available for redistribution 